\title{
Analysis of Floor Diaphragm in Multi - Storied Reinforced Concrete Building
}

\author{
Jadhav Anupriya Pramod ${ }^{1}$, S.A. Karale ${ }^{2}$, U.S. Ansari ${ }^{3}$ \\ Department of Civil Engineering, SND COE \& Research Center, Bhabulgaon, Yeola, Nashik, Maharashtra, India ${ }^{1,2,3}$
}

\begin{abstract}
The paper presents the methods of analysis of slabs as floor diaphragms. First, a framed building with \&without considering shear walls is being modeled and analyzed using Staad-Pro Software. There are three types of Floor Diaphragm: a) Flexible Diaphragm, b) Rigid Diaphragm, c) Semi-Rigid Diaphragm. All the types of Floor Diaphragms are being analyzed with increase in floor rise as 7-storey, 15-storey, and 25-storey. All Floor diaphragms results being obtained and compared with them, to get the idea of floor diaphragm suitable for a particular type of structure, here only a $3 \times 3$ bay structure with equal distances of $5 \mathrm{~m}$ is being used.
\end{abstract}

Keywords: Diaphragms, Floor Analysis, Flexible, Rigid, Semi-Rigid, Shear walls, Earthquake, Seismic, Lateral Loads, Vertical Lateral Load Resisting System.

\section{INTRODUCTION}

A. General:

We commonly conceive of the seismic force-resisting system as being composed of vertical elements, horizontal elements, and the foundation. The vertical elements extend between the foundation and the elevated levels, providing a continuous load path to transmit gravity and seismic forces from the upper levels to the foundation. The horizontal elements typically consist of diaphragms, including collectors. Diaphragms transmit inertial forces from the floor system to the vertical elements of the seismic force-resisting system. They also tie the vertical elements together and thereby stabilize and transmit forces among these elements as may be required during earthquake shaking Diaphragms are required to be designed as part of the seismic force-resisting system of every new building assigned to Seismic Design Category.

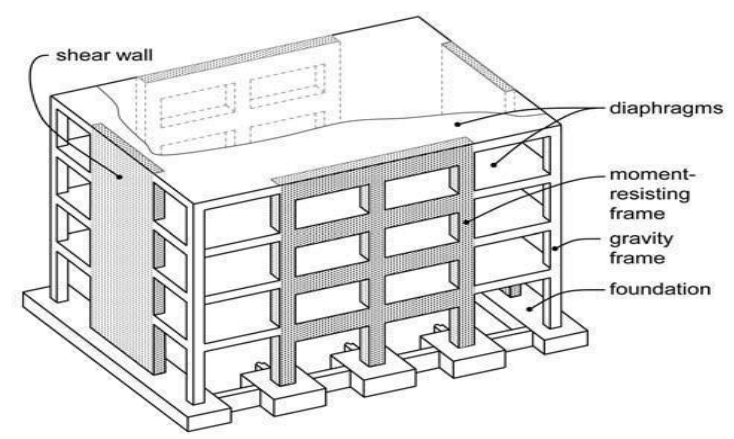

Figure: 1 Isometric View of A Basic Building

Although horizontal elements can consist of truss elements or horizontal diagonal bracing, in most cases diaphragms are constructed as essentially solid, planar elements made of wood, steel, concrete, or combinations of these. Concrete diaphragms can be conventionally reinforced or prestressed, and can be cast-in-place concrete, topping slabs on metal deck or precast concrete, or interconnected precast concrete without topping. The scope of this Guide is restricted to concrete diaphragms, conventionally reinforced.

Classification Of Diaphragms:- Rigid, Flexible, Semi rigid

\section{PROCEDURE OF ANALYSIS}

A. Roles of diaphragms:

a) Resist gravity loads.

b) Provide lateral support to vertical elements.

c) Resist out-of-plane forces Resist thrust from inclined columns.

d) Transfer lateral inertial forces to vertical elements of the seismic force-resisting system.

e) Transfer forces through the diaphragm.

f) Support soil loads below grade

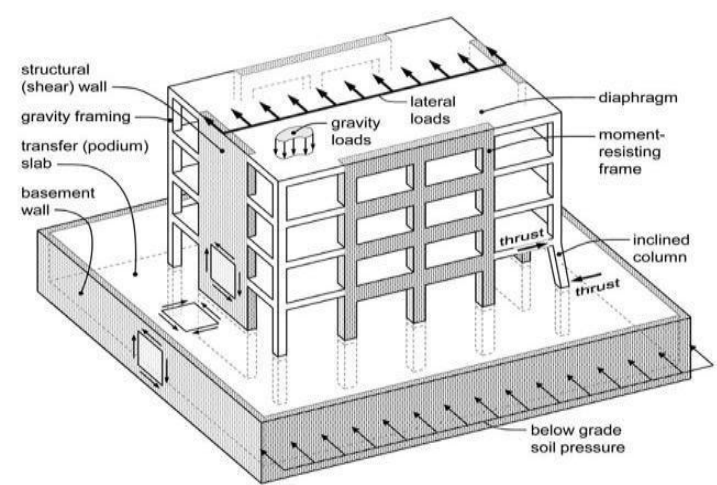

Figure: 2 Roles of Diaphragms

B. Diaphragm Components:

Diaphragms are commonly composed of various components, including the diaphragm slab, chords, collectors (also known as drag struts or distributors), and connections to the vertical elements. 


\section{Diaphragm Modeling:}

Internal forces in a diaphragm are computed using approaches that range from simple idealizations to complex computer analysis. The analysis need only be as complex as necessary to represent how lateral forces flow through the building including the diaphragms. For regular buildings in which lateral resistance is provided by similar vertical elements distributed throughout the floor plan, simple models are often adequate for determining the diaphragm forces. For buildings with irregularities or with dissimilar vertical elements, significant force transfers may occur among the vertical elements at various levels, requiring more complex models to determine the diaphragm design forces.

D. Equivalent Beam Model:

This model treats the diaphragm as a horizontal beam spanning between idealized rigid supports. The rigid supports represent vertical elements such as shear walls. For the case shown, the beam is simply supported, as the walls are at the far ends of the diaphragm. This approach may also be used with the walls located inboard of the diaphragm edges. For such cases, the beam representing the diaphragm cantilevers beyond the supports. Shear and moment diagrams are established by treating the diaphragm as if it were a beam. The shear is greatest immediately adjacent to the walls

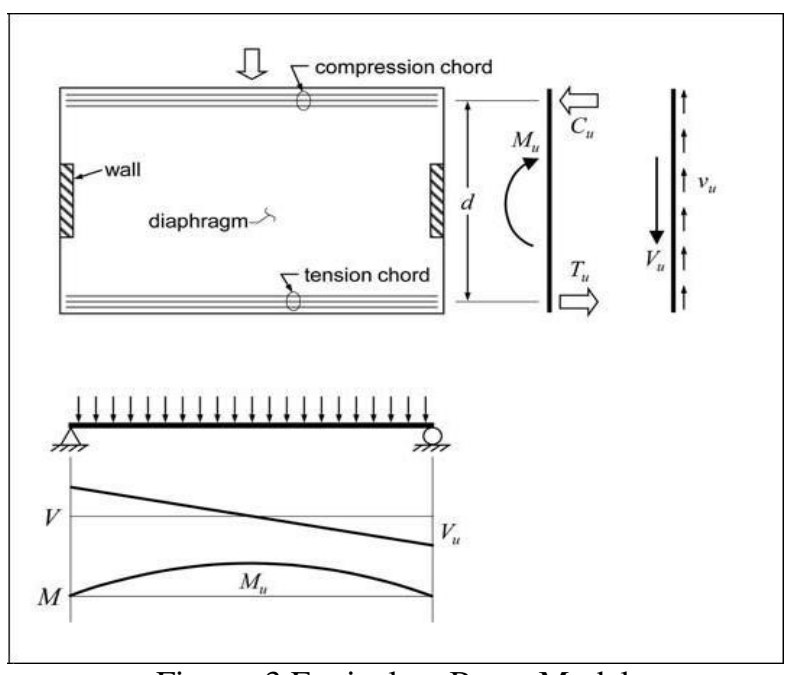

Figure: 3 Equivalent Beam Model

E. Equivalent Beam-On-Springs Model:

The equivalent beam-on-springs model envisions the diaphragm as a beam supported by flexible supports. It is most suitable in single-story buildings where spring stiffness's are readily determined. In multi-story buildings, where force transfers are more likely and where spring stiffness's are indeterminate, the approach can be used by constructing a computer model of the entire building and loading individual (a) Plan (b) Simple beam idealization Seismic Design of Cast-in-Place Concrete Diaphragms, Chords, and Collectors. The diaphragm may be treated either as a rigid beam or as a beam with flexural and shear stiffness properties.

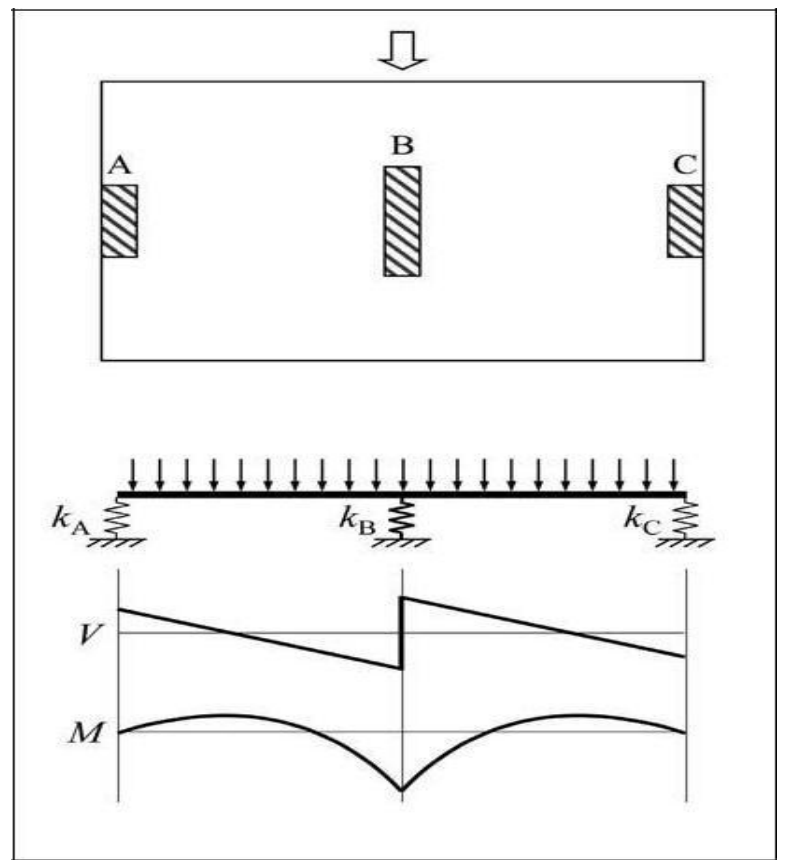

Figure 4 - Equivalent beam-on-springs model.

\section{F. Finite Element Model:}

Finite element modelling of a diaphragm can be useful for assessing the force transfer among vertical elements, addressing force transfer around large openings, assessing the impact of ramps in parking garages, and designing irregularly-shaped diaphragms. Where vertical irregularities occur in the vertical elements of the seismic force-resisting system, rigid diaphragm models may produce force "spikes" that are unrealistic and difficult to design for. By modelling diaphragm flexibility at the level of irregularity and adjacent floors, more realistic transfer distributions can be obtained.

\section{LITRETURE REVIEW}

Brief review of literature relevant to the study is presented below.

A. Dhiman Basu and Sudhir K. Jain

In this paper studied even though a rigid floor diaphragm is a good assumption for seismic analysis of most buildings, several building configurations may exhibit significant flexibility in floor diaphragm. However, the issue of static seismic analysis of such buildings for torsional provisions of codes has not been addressed in the literature. Besides, the concept of center of rigidity needs to be formulated for buildings with flexible floor diaphragms. In this paper, the definition of center of rigidity for rigid floor diaphragm buildings has been extended to unsymmetrical buildings with flexible floors. A superposition-based analysis procedure is proposed to implement code-specified torsional provisions for buildings with flexible floor diaphragms. The procedure suggested considers amplification of static eccentricity as well as accidental eccentricity. The proposed approach is applicable to orthogonal as well as no orthogonal 
unsymmetrical buildings and accounts for all possible definitions of center of rigidity.

\section{B. Gardiner R., D.K. Bull and A. J. Carr}

In this paper studied simplistic design methods are commonly employed by design engineers to determine the approximate magnitude and distribution of inertial forces in reinforced concrete floor diaphragms of multi-storey buildings. Various researchers have identified that the commonly employed simplistic design method, the Equivalent Static Analysis method, in some cases, provides a poor representation of the true structural response. This research investigates the magnitude and trends of forces in concrete floor diaphragms, with an emphasis on transfer forces, under seismic loading. This research considers the following items: inertial forces which develop from the acceleration of the floor mass; transfer forces which develop from the interaction of lateral force resisting elements with different deformation patterns, such as wall and frame elements; and variation of transfer forces due to different strengths and stiffness of the structural elements. The magnitude and trends of forces in the floor diaphragms have been determined using 2-dimensional inelastic time history analysis. Trends have been identified which will aid the improvement of seismic floor diaphragm design methods.

\section{Morteza Moeini, Behzad Rafezy:}

All the seismic codes generally accept that in most cases the floor diaphragms may be modeled as fully rigid without in-plane deformability. Even though a rigid floor diaphragm is a good assumption for seismic analysis of the most buildings, several building configurations may exhibit significant flexibility in floor diaphragms. In these configurations, some codes like (EC8, NZS4203, GSC2000) set certain qualitative criteria related to the shape of the diaphragm, while some others (ISC-2800, UBC-97, SEAOC-90, FEMA-273) set quantitative criteria relating the in-plane deformation of the diaphragm with the average drift of the associated story.

For the majority of buildings, floor diaphragms offer the most economical and rational method of resisting the lateral forces, since they are ordinarily included in the buildings to support the vertical workloads. It is thus, of the utmost importance, that they must be provided with sufficient in-plane stiffness and strength, together with efficient connections to the vertical structural elements. Muto (1974) used a beam with bending and shear deformation effects to simulate the behavior of flexible floors in buildings. Jain (1984) also used this beam including flexible and shear deformation effects to generate a solution to find the flexible-floor effect under the dynamic analysis

\section{OBJECTIVES}

A. Does Flexural Stiffness of the Slab plays vital role in Transferring of Forces through Diaphragm action to the Vertical lateral force resisting elements?
B. B. The slabs observed to act as a deep beam in transmitting horizontal loads from the slabs to the columns. For the buildings without shear walls, this study should impact the rigid floor model to be accurate as flexible \& semi-rigid model.

C. For the buildings with shear walls, the rigid floor models should not be same for flexible floor \& semi

- rigid floor models for the lateral stiffness of the shear wall system.

D. To observe the results of flexible \& semi-rigid diaphragm are identical in the cases mention.

E. Analysis for base shear.

\section{METHODOLOGY}

A. Building type and material Properties

B. Type of Structure: RCC moment resisting Framed

Building.

a. Without Shear wall.

b. With Shear wall.

C. Material Properties: Concrete M 25, Density $=24$ $\mathrm{KN} / \mathrm{m}^{3}$, Young's Modulus $(\mathrm{E})=21718 \mathrm{~N} / \mathrm{mm}^{2}$, Poison's Ratio $=0.17$

\section{Building Details}

$\begin{array}{ll}\square \text { Type of Building } & \text { : Residential apartment } \\ \text { G+7, G+15, G+25. } \\ \square \text { Location } & : \text { Mumbai (zone 3). } \\ \square \text { Zone factor } & : \quad 0.16 \\ \square \text { Basic wind Speed } & : \quad 44 \mathrm{~m} / \mathrm{s} . \\ \square \text { Ground condition } & : \text { Medium soil. } \\ \square \text { Importance factor } \quad: \quad 1 \\ \quad \square \quad \text { Response reduction factor : } 5 \\ \square \text { Damping Ratio } \quad: 5\end{array}$

E. Loads on Building :

- Selfweight of the Structure.

- Dead load: $1.5 \mathrm{KN} / \mathrm{Sq} . \mathrm{m}$

- Live load: $3 \mathrm{KN} / \mathrm{Sq} . \mathrm{m}$

- Earthquake load: Along X \& Z Directions.

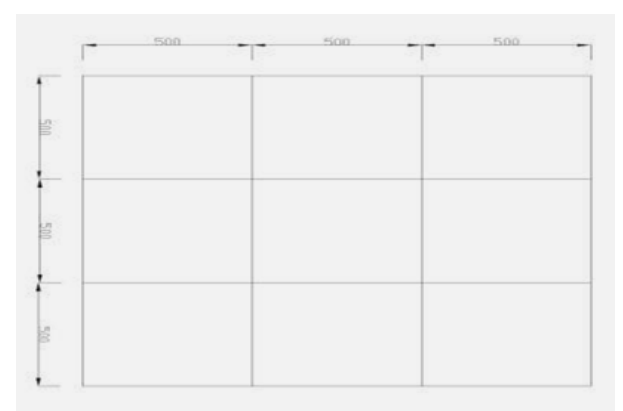

Figure 5: Showing the Typical Floor Plan of the RC Building. 
F. Analyzing Steps using STAAD.Pro 2007: $\square$ Creating the Geometry of the model.

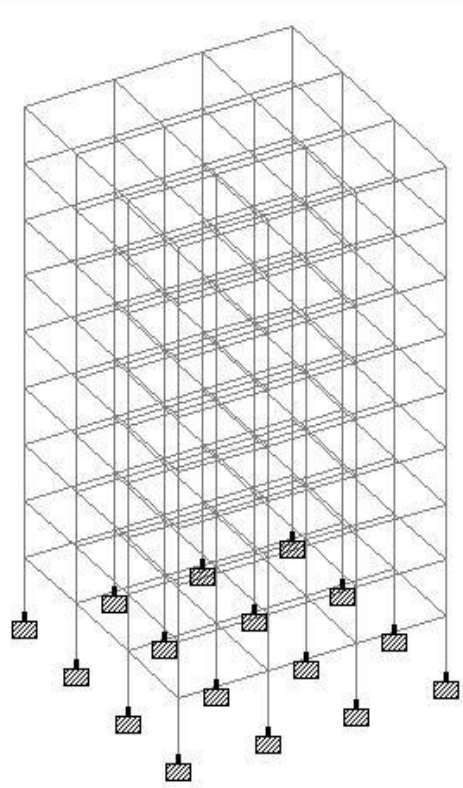

Figure 6 Typical Geometry of the model $(\mathrm{G}+7)$ in Staad.Pro

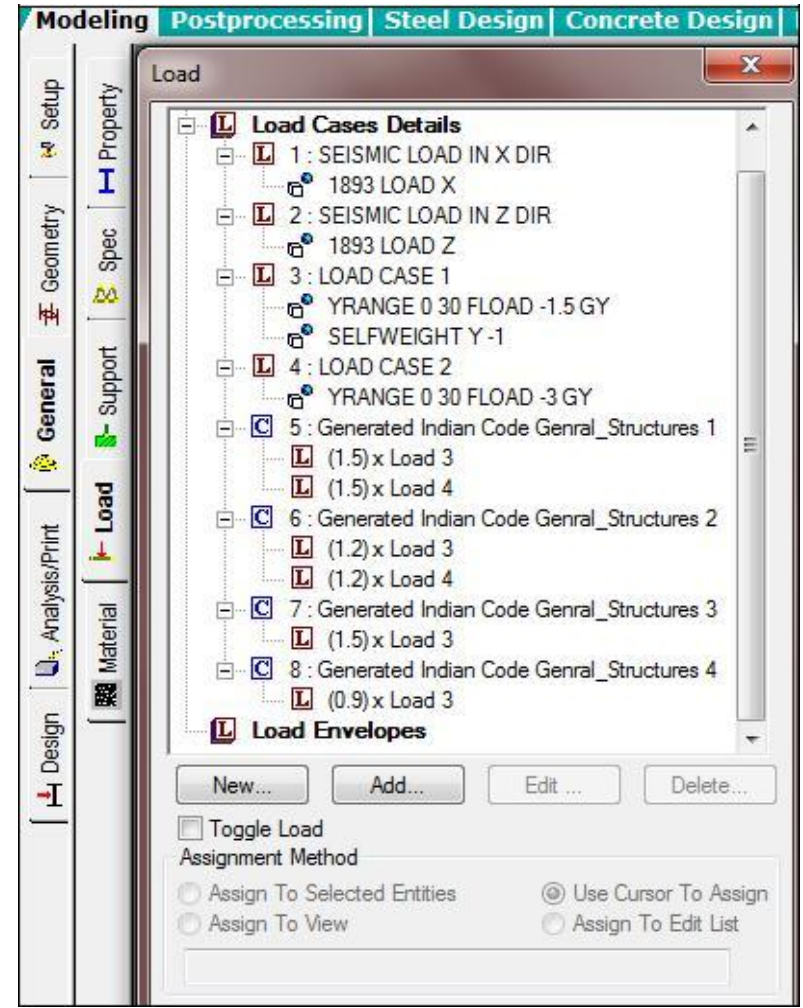

Figure 8 Showing Load Case Details in Staad.Pro

- Defining the Sections \& Material Properties of the Structural elements in the model.

- Defining the support condition to be provided to the structural model.

- Assigning the Sections \& Material Properties to the Structural elements in the model.

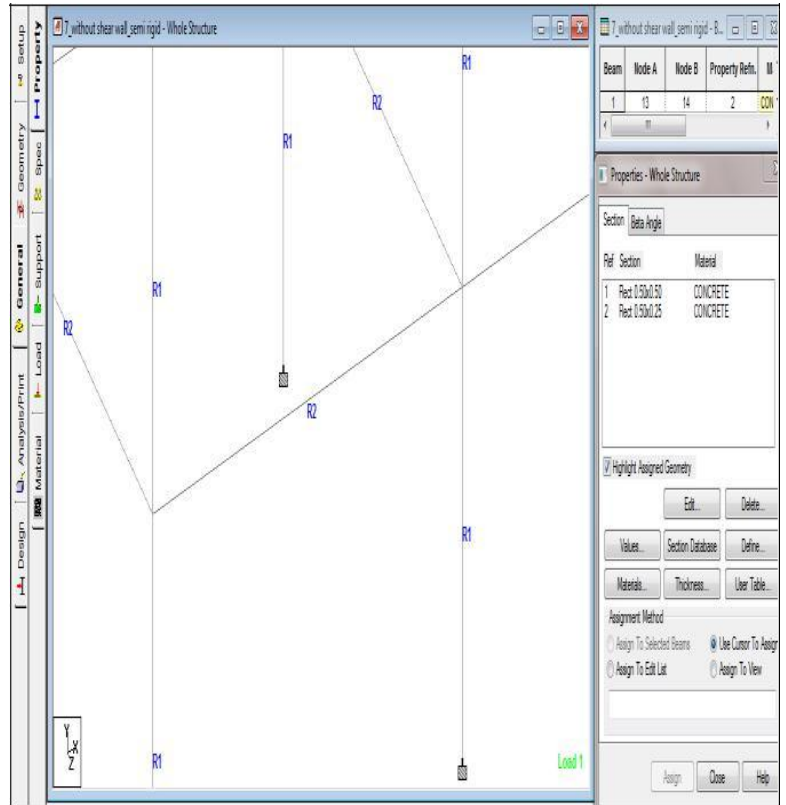

Figure 7: Showing Assigned properties of elements in Staad.Pro

- Defining the Load Case details \& Type of the loads.

- Assigning the loads to the Structural elements.

- Assigning the Support condition to the model.

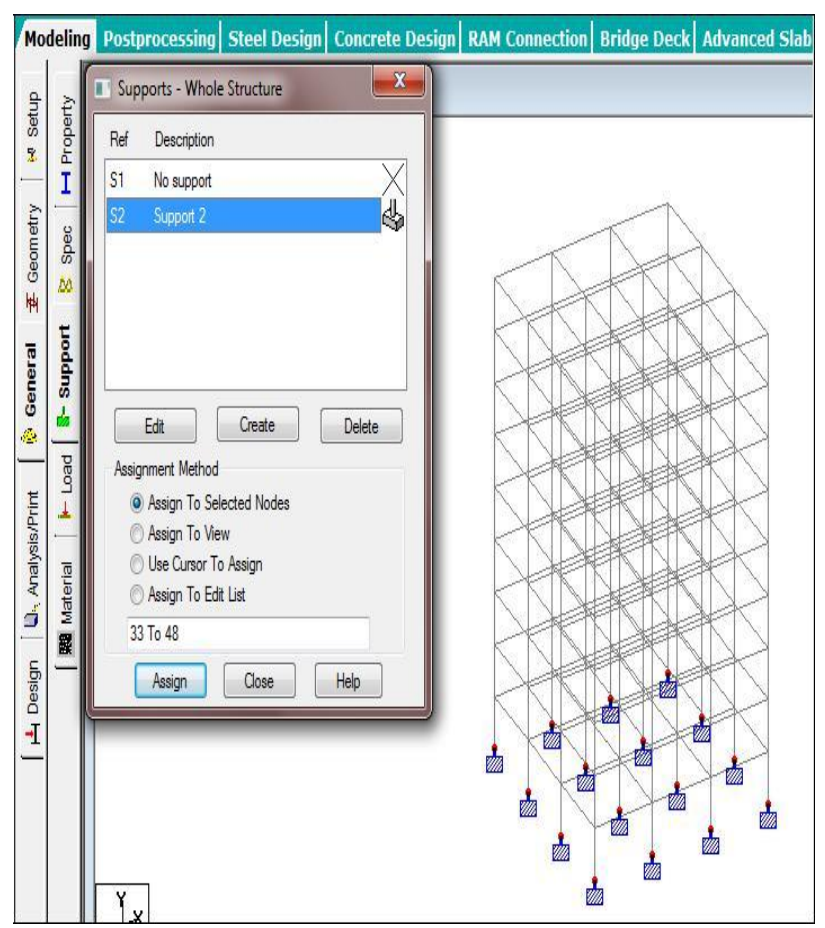

Figure 9 Showing Support Condition in Staad.Pro

Problem statement- analysis of a portal frame as shown in the figure: 
Vol. 4, Issue 3, March 2017

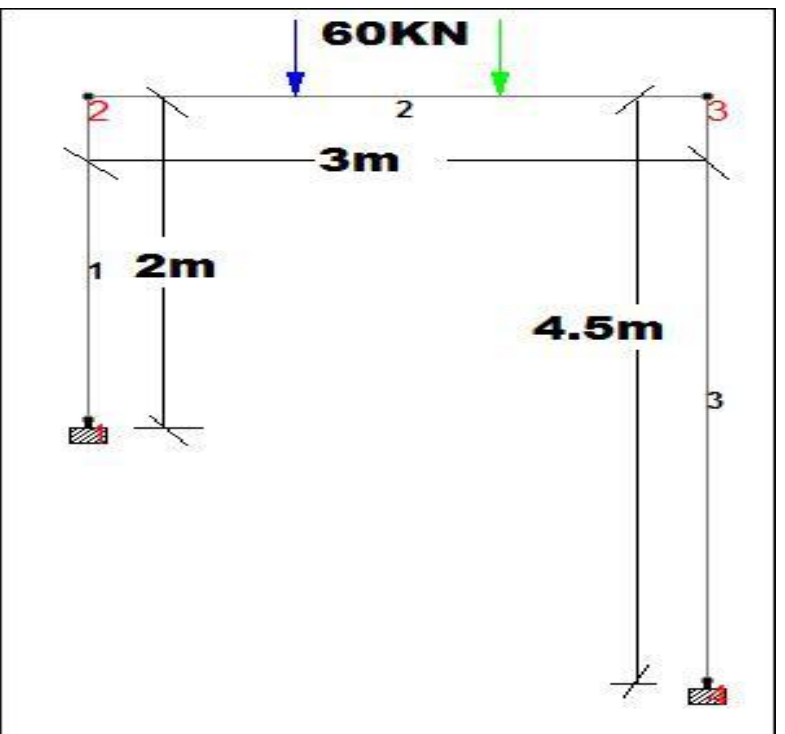

G. Solution: we first calculated the distribution factors as given in the Table

\begin{tabular}{|l|l|l|l|l|}
\hline joint & member & $\begin{array}{l}\text { Relative } \\
\text { stiffness }\end{array}$ & $\begin{array}{l}\text { Total relative } \\
\text { stiffness }\end{array}$ & $\begin{array}{l}\text { Distribution } \\
\text { factor }\end{array}$ \\
\hline 2 & $2-1(1)$ & $\mathrm{I} / 2$ & $5 \mathrm{I} / 6$ & $3 / 5$ \\
& $2-3(2)$ & $2 \mathrm{I} / 6$ & & $2 / 5$ \\
\hline 3 & $3-2(2)$ & $3 \mathrm{I} / 9$ & $5 \mathrm{I} / 9$ & $3 / 5$ \\
& $3-4(3)$ & $2 \mathrm{I} / 9$ & & $2 / 5$ \\
\hline
\end{tabular}

(a) Non-sway analysis Fixed end moments:

M 1-2= M 2-1=M3-4=M 4-3=0

$\mathrm{M} 2-3=-\left[60 / 3^{2}\right]\left(1 \times 2^{2}+2 \times 1^{2}\right)=40 \mathrm{kN}-\mathrm{m} \mathrm{M} \mathrm{3}-2=+40$

$\mathrm{kN}-\mathrm{m}$

Table 4-2 -Moment Distribution for Non-Sway Analysis:

\begin{tabular}{|c|c|c|c|c|c|}
\hline \multirow{2}{*}{\begin{tabular}{|l|}
$3 / 5$ \\
0
\end{tabular}} & \multicolumn{2}{|c|}{$2 / 5$} & \multicolumn{2}{|c|}{$3 / 5$} & $2 / 5$ \\
\hline & $\begin{array}{l}0 \\
24\end{array}$ & $\begin{array}{l}-40 \\
16\end{array}$ & $\begin{array}{l}40 \\
24\end{array}$ & $\begin{array}{l}0 \\
-16\end{array}$ & 0 \\
\hline 12 & 7.2 & & & -3.2 & -8 \\
\hline 3.6 & 1.44 & $\begin{array}{l}-2.40 \\
0.96\end{array}$ & \begin{tabular}{|l|}
2.4 \\
-1.44
\end{tabular} & -0.96 & -1.60 \\
\hline 0.72 & 0.43 & $\begin{array}{l}-0.72 \\
0.29\end{array}$ & $\begin{array}{l}0.48 \\
-0.29\end{array}$ & -0.19 & -0.48 \\
\hline 0.22 & 0.09 & $\begin{array}{l}-0.15 \\
0.06\end{array}$ & $\begin{array}{c}0.15 \\
-0.09\end{array}$ & -0.06 & -0.10 \\
\hline 0.05 & 0.03 & $\begin{array}{l}-0.05 \\
0.02\end{array}$ & $\begin{array}{l}0.03 \\
-0.02 \\
\end{array}$ & -0.01 & -0.03 \\
\hline 16.59 & 33.19 & -33.19 & +20.42 & -20.42 & -10.21 \\
\hline
\end{tabular}

So horizontal reaction at $1=16.59+33.19 / 2=24.98 \mathrm{kN}$.

Horizontal reaction at $4=-20.42-10.21 / 4.5=-6.8067 \mathrm{kN}$

Therefore net sway force $=24.89-6.8067=18.0833 \mathrm{kN}$. (b) sway analysis:-

Now the frame will be analyzed for a sway force of $18.0833 \mathrm{kN}$

The ratio of the initial equivalent moments of the column is given by

$$
=\left(\mathrm{I}_{1} / \mathrm{l}_{1}^{2}\right):\left(\mathrm{I}_{2} / \mathrm{l}_{2}^{2}\right)=20.25: 4
$$

Now the moment distribution is performed choosing the above fixed end moments:

Table 4-3 -Moment Distribution for Sway Analysis:

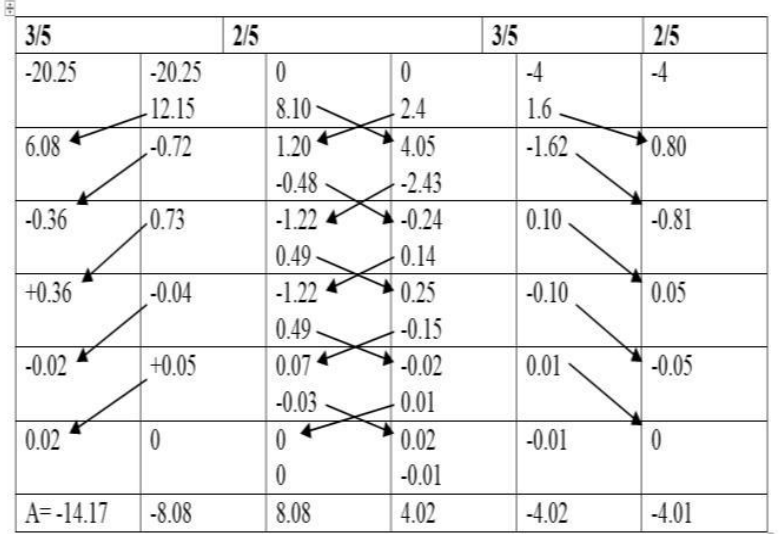

Horizontal reaction at $1=-14.17-8.08 / 2=-11.125 \mathrm{kN}$

Horizontal reaction at $4=-4.02-4.01 / 4.5=-1.7844 \mathrm{kN}$

Resolving we have total $\mathrm{S}=11.125+1.7844=12.9094 \mathrm{kN}$

Now the actual sway force of $18.0833 \mathrm{kN}$, the sway moments will be 18.0833/12.904 x A as in above table.

Table 4-4 -Final Moments.

\begin{tabular}{|l|l|l|l|l|l|l|}
\hline & 1 & 2 & 2 & 3 & 3 & 4 \\
\hline A & -14.17 & -8.08 & 8.08 & 4.02 & -4.02 & -4.01 \\
\hline $\begin{array}{l}\text { Actual } \\
\text { sway } \\
\text { moment }\end{array}$ & -19.85 & -11.31 & 11.32 & 5.63 & -5.63 & -5.62 \\
\hline $\begin{array}{l}\text { Non-sway } \\
\text { moments }\end{array}$ & 16.59 & 33.19 & -33.19 & 20.42 & -20.42 & -10.21 \\
\hline $\begin{array}{l}\text { Final } \\
\text { moments }\end{array}$ & -3.26 & 21.87 & -21.87 & 26.05 & -26.05 & -15.83 \\
\hline
\end{tabular}

(c) Reactions: $\mathrm{H} 1=9.31 \mathrm{kN}$

$\mathrm{H} 4=-9.31 \mathrm{kN} \mathrm{V} 4=61.39$

$\mathrm{kN} \mathrm{V1=120-61.39=58.61}$

$\mathrm{kN}$. 
•RESULTS OBTAINED FROM STAAD Pro

\section{Reactions}

\begin{tabular}{|c|c|c|c|c|c|c|c|}
\hline & & Horizontal & Vertical & Horizontal & & Moment & \\
\hline Node & $U C$ & $\begin{array}{l}F X \\
(\mathrm{NN})\end{array}$ & $\begin{array}{l}F Y \\
(\mathrm{NN})\end{array}$ & $\begin{array}{l}F 2 \\
(N N)\end{array}$ & $\begin{array}{c}\mathrm{MX} \\
(\mathrm{NNm})\end{array}$ & $\begin{array}{l}\text { MY } \\
(\mathrm{NNm})\end{array}$ & $\begin{array}{c}\text { MZ } \\
(\mathrm{N} M \mathrm{~m})\end{array}$ \\
\hline 1 & 1 icencentrated & 0,120 & 58.730 & 0.000 & 0.000 & 0.000 & -1.012 \\
\hline 4 & ticoncentrated & $-9,129$ & 61.270 & 0.000 & 0.000 & 0.000 & 15.462 \\
\hline
\end{tabular}

\section{Beam End Forces}

Sign convention is as the action of the joint on the beam.

\begin{tabular}{|c|c|c|c|c|c|c|c|c|}
\hline & Axial & \multicolumn{2}{|c|}{ Shear } & \multirow{2}{*}{$\frac{\text { Torsion }}{\mathrm{Mx}}$} & \multicolumn{2}{|c|}{ Bending } \\
\hline Beam & Node & $\overline{U U C}$ & $\begin{array}{l}\mathrm{FX} \\
(\mathrm{WN}) \\
\end{array}$ & $\begin{array}{l}\text { Fy } \\
(\mathrm{kN})\end{array}$ & $\begin{array}{l}\mathrm{F}_{2} \\
(\mathrm{kN})\end{array}$ & & $\begin{array}{c}\text { My } \\
(\mathrm{kNm})\end{array}$ & $\begin{array}{c}\mathrm{Mz} \\
(\mathrm{kNm})\end{array}$ \\
\hline 1 & 1 & 1.CONCEENTR & 58.884 & 9.038 & 0.000 & 0.000 & 0.000 & .3 .959 \\
\hline & 2 & 1.CONCENTR & .58 .864 & .9036 & 0.000 & 0.000 & 0.000 & 22031 \\
\hline 2 & 2 & 1:CONCENTR & 9.048 & 58.864 & 0.000 & -100.000 & 0,000 & 22.031 \\
\hline & 3 & 1.CONCENTR & .0 .048 & 61.136 & 0.000 & 80.000 & 0.000 & .25 .439 \\
\hline 3 & 3 & 1.CONCENTR & 61.136 & .9054 & 0.000 & 0.000 & 0.000 & .25 .439 \\
\hline & 4 & 1.CONCENTR & .81 .136 & 9.054 & 0.000 & 0.000 & 0.000 & $.15,304$ \\
\hline
\end{tabular}

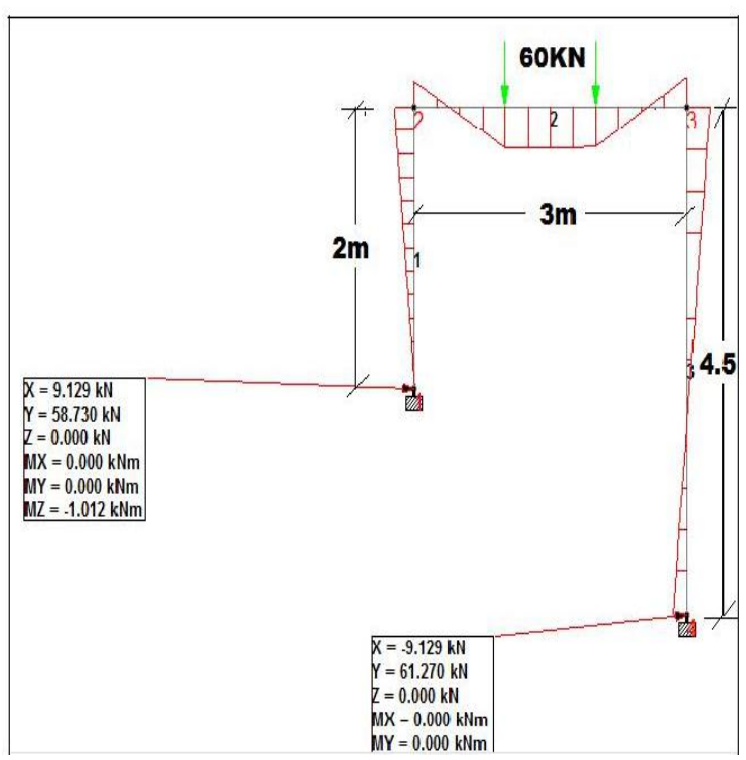

\section{CONCLUSIONS}

- Flexural Stiffness of the Slab plays vital role in Transferring of Forces through Diaphragm action to the Vertical lateral force resisting elements.

- The slabs are observed to act as a deep beam in transmitting horizontal loads from the slabs to the columns. Thus, the floor slabs play important role in transferring the horizontal loads to the lateral resisting system, i.e. the columns.

- For the buildings without shear walls, this study indicates that the rigid floor model is as accurate as flexible \& semi-rigid model.
- For the buildings with shear walls, the rigid floor models differ greatly with the flexible floor \& semi rigid floor models due to the very large lateral stiffness of the shear wall system.

- It was being observed that the results of flexible \& semi-rigid diaphragm are identical in the cases mention, but might differ with geometry non linearity.

- It is clear that base shear is greater at the centre of rigidity of the structure compared to end columns.

- It is been seen that Rigid Diaphragm is a good assumptions for Multi-Storeyed (Structures of greater height) compared to flexible \& Semi - Rigid Diaphragm.

\section{REFERENCES}

[1] Dhiman Basu" and Sudhir K. Jain" "Seismic Analysis of Asymmetric Buildings with Flexible Floor Diaphragms." 1176 / journal of structural engineering (C) asce / august 2004.

[2] D. R. Gardiner, D.K. Bull and A. J. Carr "Internal forces of concrete floor diaphragms in multi-storey buildings." NZSEE Conference (2008).

[3] By Morteza Moeini, Behzad Rafezy "Investigation into the Floor Diaphragms Flexibility in Reinforced Concrete Structures and Code Provision." Global Journal of Researches in Engineering (Feb.2011).

[4] Dr. Jubran Naddaf (1) and Alan Ross (2) "Diaphragm action in dramixtm steel fibre reinforced concrete on profiled sheet metal hybrid floor systems." 